\title{
A Comparison of the Corrosion Resistance and Wear Resistance Behavior of Cr-C, Ni-P and Ni-B Coatings Electroplated on 4140 Alloy Steel
}

\author{
Hung-Hua Sheu ${ }^{l, *}$, Jian-Huang Syu ${ }^{1}$,Yih-Ming Liu ${ }^{l}$, Kung-Hsu Hou ${ }^{2}$, Ming-Der Ger ${ }^{1 *}$ \\ ${ }^{1}$ Department of Chemical and Materials Engineering, Chung Cheng Institute of Technology, National \\ Defense University, Taoyuan City, Taiwan \\ ${ }^{2}$ Department of Power Vehicle and Systems Engineering, Chung Cheng Institute of Technology, \\ National Defense University, Taoyuan City, Taiwan \\ *E-mail: shhccit@gmail.com, mingderger@gmail.com
}

doi: $10.20964 / 2018.04 .49$

Received: 1 January 2018 / Accepted: 18 February 2018 / Published: 6 March 2018

Different coatings such as $\mathrm{Cr}-\mathrm{C}$ coatings (chromium sulfate bath), $\mathrm{Cr}-\mathrm{C}$ coatings (chromium chloride bath), Ni-P coatings and Ni-B coatings are electrodeposited on 4140 alloy steel, respectively. The corrosion and wear resistance of these coatings are studied. The experimental results show that the NiB coatings has the highest hardness (approximately at $951 \mathrm{Hv}$ ) and the best adhesion strength (approximately at $11 \mathrm{MPa}$ ), these two excellent properties lead to the $\mathrm{Ni}-\mathrm{B}$ coatings has the lowest wear rate (approximately at $0.66 \times 10^{-6} \mathrm{~mm}^{3} / \mathrm{Nm}$ ). According to the potentiodynamic polarization analysis results, it shows that Ni-B coatings has a better corrosion resistance $\left(i_{\text {corr }}=9.62 \times 10^{-7} \mathrm{~A} / \mathrm{cm}^{2}\right)$ than that of $\mathrm{Cr}-\mathrm{C}$ coatings due to its crack-free structure and higher adhesion strength. All experimental results indicate that Ni-B coatings is the most suitable coatings which can be used to protect 4140 alloy steel substrates from corrosion and wear damages, and enhance the application of 4140 alloy steel in industry.

Keywords: adhesion strength; corrosion resistance; contact angle; Ni-B coatings

\section{$\underline{\text { FULL TEXT }}$}

(C) 2018 The Authors. Published by ESG (www.electrochemsci.org). This article is an open access article distributed under the terms and conditions of the Creative Commons Attribution license (http://creativecommons.org/licenses/by/4.0/). 